\title{
Angiofollicular lymph node hyperplasia arising from the intercostal space
}

\author{
HIROYUKI MATSUDA, MASAKI MORI, KOSEI YASUMOTO, KEIZO SUGIMACHI
}

\author{
From the Department of Surgery II, Faculty of Medicine, Kyushu University, Fukuoka, Japan
}

\begin{abstract}
Angiofollicular lymph node hyperplasia (Castleman's disease) was first described in 1956 by Castleman et $a l^{\prime}$ as asymptomatic large, benign hyperplastic mediastinal lymph nodes that resembled thymoma. This disease has been reported in various sites and organs, but a careful search of published reports showed no case arising from the intercostal space. We report a case that arose in the chest wall.
\end{abstract}

\section{Case report}

A 69 year old Japanese man was admitted to Kyushu University hospital for evaluation of a long standing abnormal shadow on his chest radiograph, first detected nine years previously on a routine chest radiograph. Initially it had been $1.3 \mathrm{~cm}$ in diameter, but three years later it had grown to $2.3 \mathrm{~cm}$ and by six years it was $3.4 \mathrm{~cm}$. The patient had been in good health, without peripheral lymphadenopathy or abnormal palpable masses.

On examination there was dullness to percussion with decreased breath sounds and diminished vocal fremitus at the base of the left lung. The erythrocyte sedimentation rate was $18 \mathrm{~mm}$ in one hour, and other laboratory data were within normal limits. A chest radiograph showed a uniform shadow $5.7 \times 4.0 \mathrm{~cm}$ in the left upper field, suggesting an extrapleural tumour and a large pleural effusion (fig 1). Thoracocentesis yielded serous fluid, which showed no specific features on microbiological and cytological examination. There was no evidence of tuberculosis or malignancy in a needle biopsy specimen of the pleura.

A thoracotomy was performed via a left posterolateral incision. When the left pleural cavity was entered about $800 \mathrm{ml}$ of serous fluid was found. A mass, covered by parietal pleura, was situated on the posterolateral chest wall at the level of the $2 \mathrm{nd}-3 \mathrm{rd}$ rib. It appeared to originate in the second intercostal space and protruded into the pleural cavity. It was removed en bloc together with surrounding intercostal tissues. The postoperative course was uneventful and the patient was discharged 20 days after surgery. There has been no recurrence of either the mass or the effusion during the ensuing three years.

The resected specimen measured $5.5 \times 4.5 \times 4.5 \mathrm{~cm}$ and weighed $56 \mathrm{~g}$. It was well encapsulated with fibrous tissues and had a hard elastic consistency. The cut surface was partly yellow grey and partly dark brown, with no necrosis. On microscopic examination there were numerous small lym-

Address for reprint requests: Dr Hiroyuki Matsuda, Department of Surgery II, Faculty of Medicine, Kyushu University, Fukuoka 812, Japan.

Accepted 28 September 1987 phoid follicles, the centres of which were composed of concentrically layered large, pale cells with a squamoid appearance. In the interfollicular areas there was extensive capillary proliferation, and lymphocytes, plasma cells, and eosinophils were also present. The capillaries were lined by plump endothelial cells and ensheathed by a varying amount of hyalinised collagenous tissue (fig 2). All these findings were compatible with the hyaline vascular type of angiofollicular lymph node hyperplasia.

\section{Discussion}

Since Castleman et al first described angiofollicular lymph node hyperplasia many investigators have reported the condition under various names, including large lymphnodal hamartoma, ${ }^{2}$ follicular lymphoreticuloma, ${ }^{3}$ angiofollicular mediastinal lymph node hyperplasia, ${ }^{4}$ and angiomatous lymphoid harmatoma. ${ }^{5}$ Keller and coworkers ${ }^{6}$ divided the disease histologically into the hyaline vascular type, characterised by small hyaline vascular follicles and interfollicular capillary proliferation, and the plasma cell type, consisting of large follicles with intervening sheets of plasma cells. The hyaline vascular type, which accounts for $90 \%$ of cases, does not give rise to systemic manifestations. The much rarer

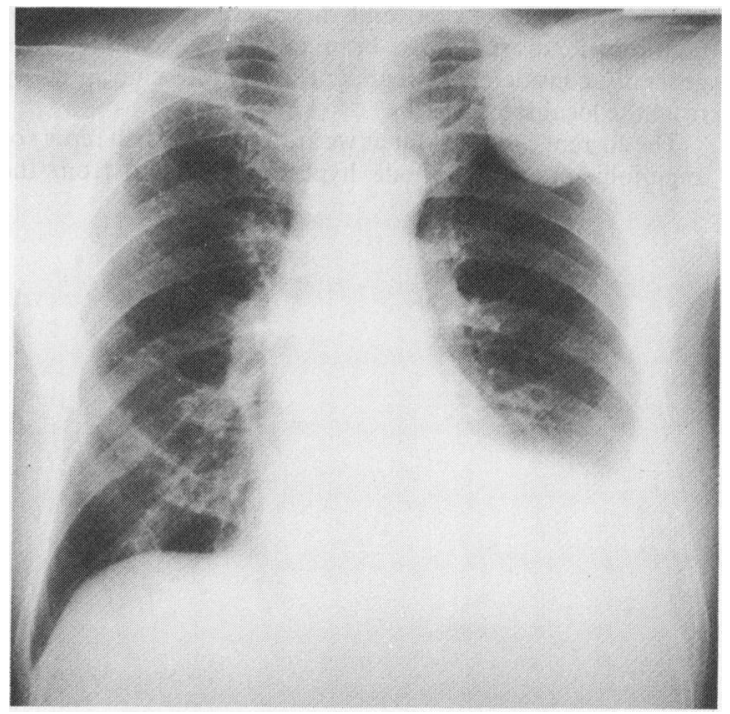

Fig 1 Chest radiograph at admission showing a large, uniform tumour shadow, $5.7 \times 4.0 \mathrm{~cm}$ in size, in the left upper lung field, associated with a large pleural effusion. 


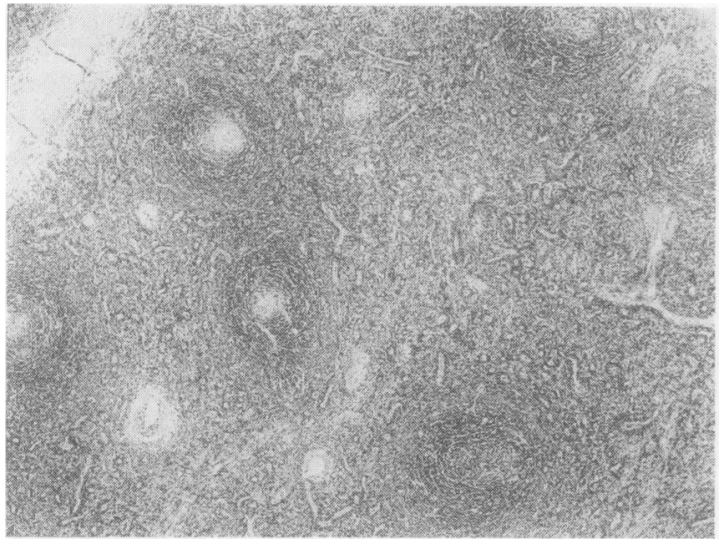

Fig 2 Tumour section consisting of proliferating lymph follicles with germinal centres. Note also the proliferation of finely arborising vessels in the interfollicular space.

(Haematoxylin and eosin.)

plasma cell variant, on the other hand, is associated with anaemia, a raised erythrocyte sedimentation rate, hyperglobulinaemia, hypoproteinaemia, and fever.

These lesions are benign and grow slowly. Our patient had been followed for nine years, during which time the mass had gradually increased in size from $1.3 \mathrm{~cm}$ to $4.0 \mathrm{~cm}$ in diameter. The doubling times in the three year periods were calculated to be 386 days, 819 days, and 1551 days. Tanaka et al reported data on a patient followed for four years and here the doubling time was 501 days, the mass enlarging from $2 \cdot 3$ to $4.5 \mathrm{~cm}$ during four years.

Angiofollicular lymph node hyperplasia has a predilection for certain sites and organs. It most commonly arises in the mediastinum, followed by the neck, lung, retroperitoneum, intrapelvic cavity, axilla, and mesentery. ${ }^{8}$ A few cases of multicentric disease have been described, but these are generally considered to represent a separate clinical entity from the localised tumour.

The current case is, so far as we are aware, the first report of angiofollicular lymph node hyperplasia arising from the intercostal space and presenting as a chest wall tumour. $\overrightarrow{\vec{F}}$

Another interesting finding was the accompanying pleurat effusion. Although typically the hyaline vascular type tumour is usually without systemic manifestation the effusiog in our patient seemed to be related to the disease as disappeared rapidly after excision of the lesion.

An unusual reactive lymphoid response, a hamartomatous process, and true lymphoid tumour development have af been suggested for the pathogenesis. A viral causation, with $\vec{\oplus}$ decreased T4:T8 lymphocyte ratio, has been proposed if several recent studies. ${ }^{910}$ Immunocytochemical analysis was not, however, carried out in the present case.

Surgical removal seems the most appropriate treatmes since there has been no reccurrence of either the lesion or the effusion after three years of postoperative follow up.

\section{References}

1 Castleman B, Iverson L, Menendez P. Localised mediastinal lymph node hyperplasia resembling thymoma. Cances 1956;9:822-30.

2 Abell MR. Lymphnodal hamartoma versus thymic choristoma of pulmonary hilum. Arch Pathol 1957;64:584-8.

3 Zettergren L. Probably neoplastic proliferation of lymphoid tissu位 (follicular lympho-reticuloma). Acta Pathol Microbiol Scant? 1961;51:113-26.

4 Harrison EG, Bernatz PE. Angiofollicular mediastinal lymp node hyperplasia resembling thymoma. Arch Pathg 1963;75:284-92.

5 Tung KSK, McCormack LT. Angiomatous lymphoid ha5̆ matoma. Cancer 1967;20:525-36.

6 Keller AR, Hochholzer L, Castleman B. Hyalinevascular and plasma cell types of giant lymph node hyperplasia of the mediastinum and other location. Cancer 1972;29:670-83.

7 Tanaka T, Kobayashi K, Sho T, Hamazaki M. Castleman' lymphoma among Japanese population. Acta Pathol JaD 1976;26:547-59.

8 Harigaya K, Mikata A, Kageyama K, Kameya T, Shimosato Histopathological study of six cases of Castleman's tumor. Acr Pathol Jap 1975;25:355-74.

9 Dickson D, Ben-Ezra JM, Reed J, Flax H, Janis R. Multicentrio giant lymph node hyperplasia, Kaposi's sarcoma, and lym. phoma. Arch Pathol Lab Med 1985;109:1013-8.

10 Mohamedani AA, Benett MK. Angiofollicular lymphoid hype plasia in a pulmonary fissure. Thorax 1985;40:686-7. 